Article

\title{
Comparison of the Farming System and Carbon Sequestration between Conventional and Organic Rice Production in West Java, Indonesia
}

\author{
Masakazu Komatsuzaki ${ }^{1}{ }^{*}$ and M. Faiz Syuaib ${ }^{2}$ \\ 1 College of Agriculture, Ibaraki University, 3-21-1 Ami, Inashiki, Ibaraki 300-0393, Japan \\ 2 Department of Agricultural Engineering, Bogor Agricultural University, JI Meranti, Kampus IPB \\ Darmaga, Bogor, 16680, Indonesia; E-Mail: mfsyuaib@yahoo.com \\ * Author to whom correspondence should be addressed; E-Mail: komachan@mx.ibaraki.ac.jp; \\ Tel.: +81-29-888-8707; Fax: +81-29-888-8707.
}

Received: 1 February 2010; in revised form: 20 February 2010 / Accepted: 1 March 2010 /

Published: 22 March 2010

\begin{abstract}
Organic farming provides many benefits in Indonesia: it can improve soil quality, food quality and soil carbon sequestration. This study was designed to compare soil carbon sequestration levels between conventional and organic rice farming fields in west Java, Indonesia. The results from soil analysis indicate that organic farming leads to soil with significantly higher soil carbon storage capacity than conventional farming. Organic farming can also cut some farming costs, but it requires about twice as much labor. The sharecropping system of rice farming in Indonesia is highly exploitative of workers; therefore, research should be conducted to develop a fairer organic farming system that can enhance both local and global sustainability.
\end{abstract}

Keywords: organic farming; rice farming system; soil carbon sequestration; weeding tools; working time; appropriate technology

\section{Introduction}

During the latter half of the 20th century, intensive agriculture increased crop yields and was successful in meeting the growing demand for food, but it also degraded the natural resources upon which agriculture depends-soil, water resources, and natural genetic diversity [1,2]. Today, 
conventional agriculture is built around two related goals: the maximization of production and the maximization of profit. In pursuit of these economic goals, a host of practices have been developed without regard for their unintended long-term consequences and without consideration of the ecological dynamics of agroecosystems. Millennium Ecosystem Assessment [3] revealed that the overuse and mismanagement of pesticides poisons the water and soil, while nitrogen and phosphorus inputs and livestock wastes have become major pollutants of surface water, aquifers, and coastal wetlands and estuaries. These situations are also serious and cause severe ecological problems in the tropical biological environment, especially in Indonesia.

With a population of 230 million, Indonesia is the world's fourth most populous country, and its population is growing at a rate of $1.4 \%$ per year. Agriculture plays a substantial role in the Indonesian economy, involving about $45 \%$ of the population, and accounting for $19 \%$ of the gross domestic product and more than $60 \%$ of the value of non-oil exports. Over the last two decades, annual agricultural output has grown by $4 \%$ [4]. In Indonesia, modern farming technologies have kept production apace with population growth, but major problems with food distribution still plague many communities and regions.

Indonesia is also a richly bio-diverse tropical agro-ecosystem. About 95\% of the land surface of Indonesia is still covered by vegetation, either as tropical rain forest, woodland, mangrove, agricultural fields or grassland, which contain a variety of indigenous flora and fauna, many of which are unique species that do not occur in any other place in the world [5].

However, increasing synthetic chemical input to cropland to meet the increasing demand for food has led to decreasing biodiversity in agricultural areas. The soil management system, which is overly dependent on chemical fertilizers, has also led to decreasing soil organic matter and soil quality [6]. Currently, Indonesia has a total of 40,000 hectares under organic cultivation, about 0.12 percent of its total land area [7].

After the "Green Revolution" program was launched in the late 60s, the application of chemical fertilizer dramatically increased due to governmental encouragement to achieve food self-sufficiency. Since then, farmers have been using blended fertilizer $\left(\mathrm{N}, \mathrm{P}_{2} \mathrm{O}_{5}\right.$, and $\left.\mathrm{K}_{2} \mathrm{O}\right)$ with the recommended composition. Fertilizer consumption in the agricultural sector increased five-fold between 1975 and 1990 and increased slightly further afterwards. However, as a result of the Asian economic crisis in 1998, the government reduced the subsidies for fertilizers, resulting in increasing agricultural input costs. Since that time, farmers have been reducing the use of chemical fertilizers and have started to utilize more organic fertilizer and improve the methods for its application [5].

Public awareness of what "organic agriculture" means, as well as consumer demand for organic crops, are currently very low in Indonesia, where the benefits of organic farming are understood by only few who are concerned about food safety for their own health. However, through the efforts of NGOs and the government of Indonesia, people are developing interest in environmentally friendly organic farming [7]. Organic farming provides a lot of benefits to the farming system in Indonesia, because it can improve soil and food quality, and increase the soil organic carbon (SOC) storage in the soil. For global environmental conservation, this soil management strategy has great potential to contribute to carbon sequestration, because the carbon sink capacity of the world's agricultural and degraded soil is $50-66 \%$ of the historic carbon loss of $42-72$ pentagrams ( $1 \mathrm{Pg}=10^{15} \mathrm{~g}$ ), although actual carbon storage in cultivated soil may be smaller if climate change leads to increasing 
mineralization [8]. The importance of SOC in agricultural soil is, however, not controversial, because SOC helps to sustain soil fertility and conserve soil and water quality, and these compounds play a variety of roles in the nutrient, water, and biological cycles.

Organic farming also has great potential to improve soil carbon storage $[9,10]$. However, only a few studies have been conducted in Indonesia, and there is little data for comparing soil carbon storage between organic farming and conventional farming. In addition, the organic farming system and associated farm work had not been studied in Indonesia. Therefore, this research was designed to compare soil carbon sequestration levels in conventional and organic farming systems for rice production on the island of Java, Indonesia

\section{Materials and Methods}

\subsection{Study Area}

The study area was the city of Bogor, located in the Cisadane watershed, west Java, Indonesia. The Cisadane River flows through urban areas from Bogor to Jakarta, the capital of Indonesia, and is a major rice and vegetable production area. Soil type is Latosole. Organic and conventional rice farmer groups for the study were selected from the Situgede district of Bogor. Figure 1 illustrates the geographical location of the studied sites in west Java, Indonesia.

Figure 1. Geographical location of studied sites in west Java, Indonesia.

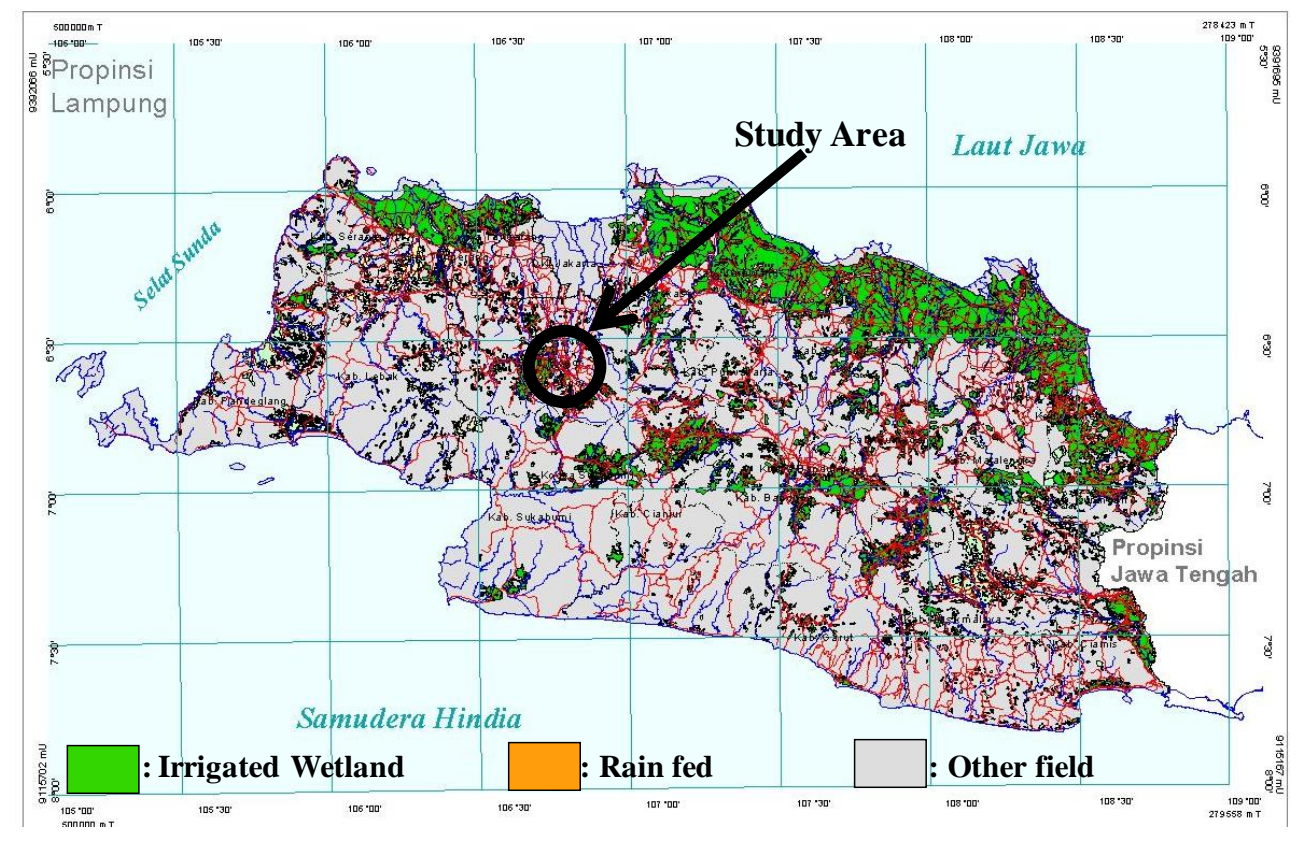

\subsection{Field Investigations}

Field investigations were conducted in March and September 2008 and September 2009, and details of farming practices and chemical or organic fertilizer application were obtained from interviews with conventional and organic rice farmers. For organic rice production, farmers use a self-produced 
organic fertilizer called "bochashi", which is composed of $10 \%$ rice bran, $20 \%$ rice chaff, and $70 \%$ cow manure (in volume). Nutrient component of this organic fertilizer are $28.29 \%$ carbon, $0.35 \%$ nitrogen, $0.17 \%$ phosphorus, $2.31 \%$ potassium, $1.87 \%$ calcium, and $0.42 \%$ magnesium (on a dry matter basis). Based on the interview data, the cost for farming and amount of labor required for farming were calculated. The prices of materials were also obtained through interviews with merchants. Figure 2 illustrates the difference between conventional and organic rice production systems. We also interviewed about the true state of organic rice production to workers.

Figure 2. Comparison of farm management systems between conventional and organic rice production in west Java, Indonesia.

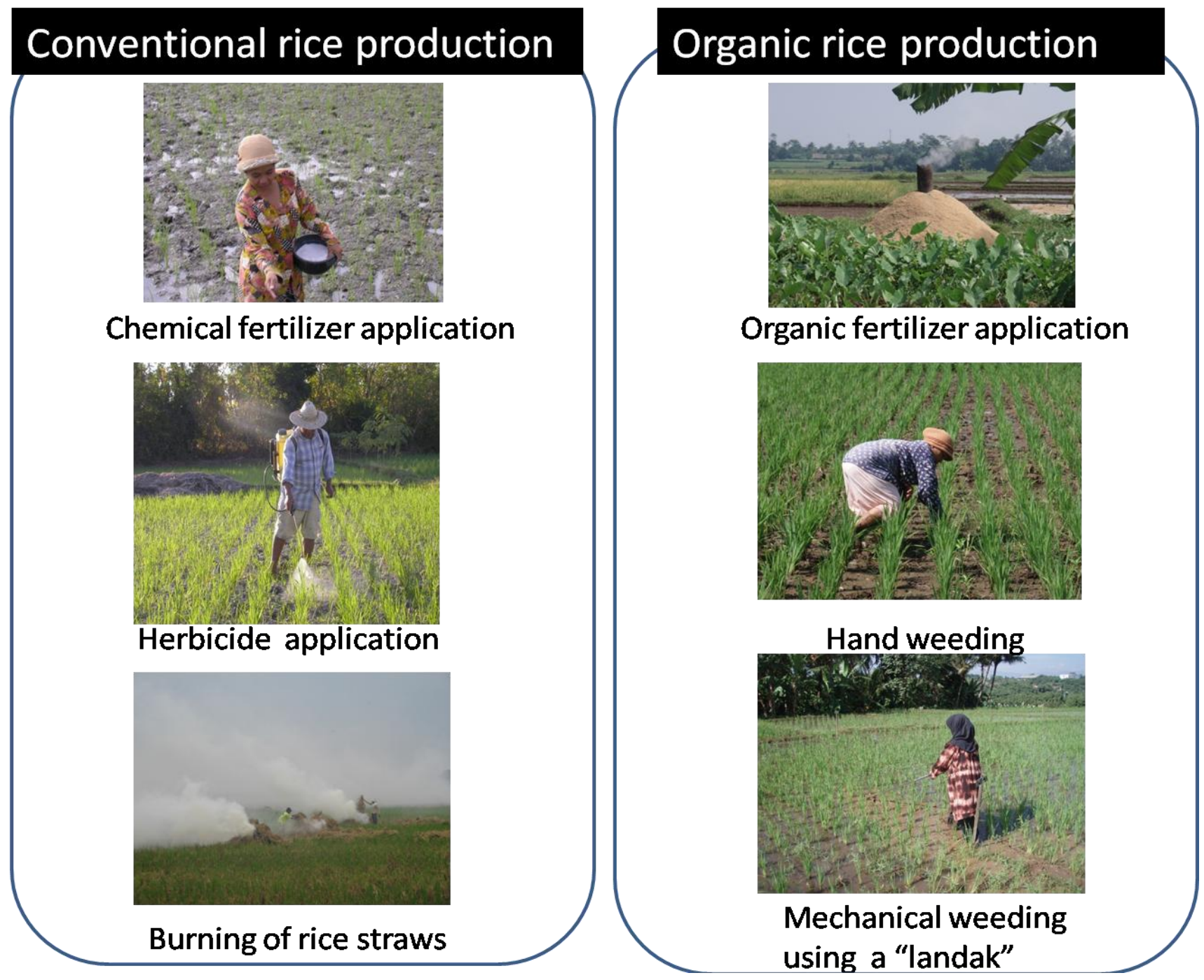

\subsection{Soil and Crop Yield Analysis}

Organic fields were converted to organic from conventional farming after August 2003, and we examined the 13th rice crop grown after the switch to organic management. Organic fields did not receive the organic certification. Conventional fields continued to be fertilized with chemical input and no organic fertilizer. Both fields of organic and conventional rice production were located in the same area. 
Topsoil samples (from a depth of $0-10 \mathrm{~cm}$ ) were taken from three conventional and three organic rice fields in September 2008 with a $55.8 \mathrm{~mm}$ diameter soil core sampler. Soil core volume was registered and water content determined (gravimetrically) on sample aliquots, to calculate bulk density (BD). Soil samples were dried at $50{ }^{\circ} \mathrm{C}$, ground to pass a $2 \mathrm{~mm}$ sieve and stored until analysis. Organic carbon content was analyzed by the Walkley-Black Procedure [11] and soil organic carbon storage (SCS) was calculated as following.

$$
\mathrm{SCS}\left(\mathrm{Mg} \mathrm{ha}^{-1}\right)=\mathrm{BD} \times \mathrm{SOC} \times \mathrm{DP} \times 100
$$

where, BD: bulk density $\left(\mathrm{g} \mathrm{mL}^{-1}\right)$; SOC: soil organic carbon content (\%); DP: soil depth (m).

To obtain the soil carbon distribution between conventional and organic rice fields, soil samples were collected from different fields managed by the fields mentioned above (where topsoil samples were taken), using a post hole auger at depth of 0-2.5, 2.5-7.5, 7.5-15, and 15-30 cm at harvest of rice in September 2009. These soil samples were also analyzed for organic carbon content by the above mentioned methods.

Rice yields were estimated by air dried subsamples taken using a $1 \mathrm{~m}$ row section after manually harvesting whole fields in September 2008.

\section{Results and Discussion}

The soil in the organic farming system showed higher soil carbon content than conventional soils after four years of continuous organic farming, however, there were no significant differences in soil bulk density between the two farming systems (Table 1). Soil carbon storage in organic farming was significantly increased compared with conventional farming. These differences were also obvious in soil carbon content profile, which was significantly higher in the organic field than the conventional field, especially in the top $10 \mathrm{~cm}$ soil layer (Figure 3). However, soil carbon contents are somewhat lower in Figure 3 compare with Table 1. This difference suggests that there was diversification of soil carbon content depending on the site specific location, however, organic fields showed higher carbon content than the conventional fields in both 2008 and 2009.

Table 1. Comparison of soil carbon sequestration between organic and conventional rice fields in the top $10 \mathrm{~cm}$ soil depth.

\begin{tabular}{|c|c|c|c|}
\hline & $\begin{array}{c}\text { Soil Bulk Density } \\
\mathrm{g} \mathrm{m}^{-1}\end{array}$ & $\begin{array}{c}\text { Carbon Content } \\
\% \\
\end{array}$ & $\begin{array}{c}\text { Soil Carbon Storage } \\
\mathrm{Mg} \mathrm{ha}^{-1} \\
\end{array}$ \\
\hline Organic & 0.88 & 2.89 & 25.0 \\
\hline Conventional & 0.80 & 2.22 & 17.6 \\
\hline Significance & NS & $*$ & $* *$ \\
\hline
\end{tabular}


Figure 3. Comparison of soil carbon content profile between organic and conventional rice fields in the top $30 \mathrm{~cm}$ soil depth.

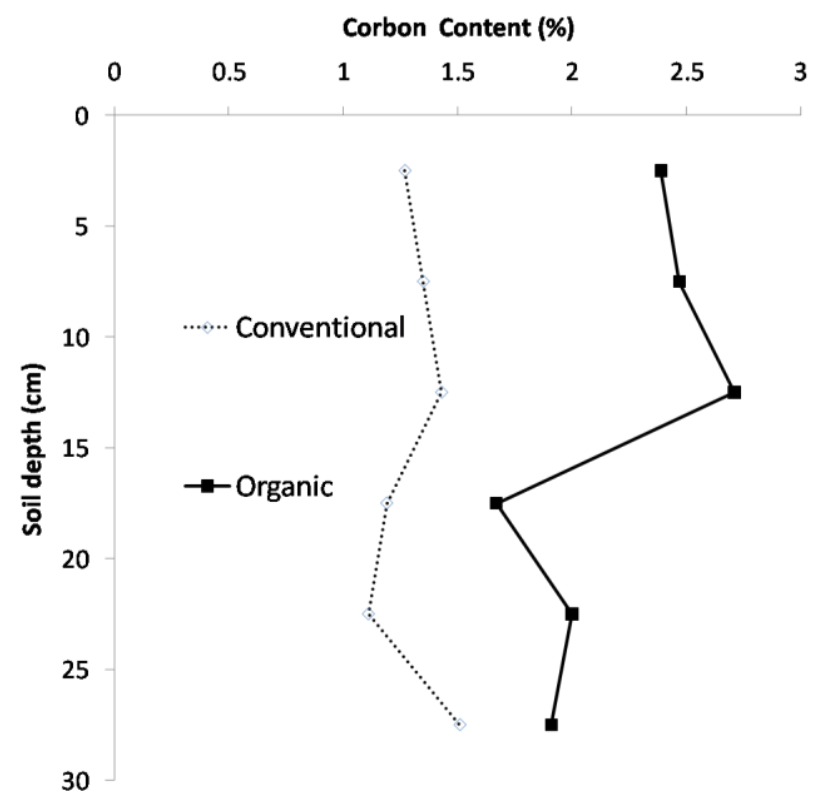

Using Table 1 data, we can estimate the soil carbon sequestration ability. Organic farming can increase 1.85 ton $\mathrm{C}$ per hectare per year compared with the conventional farming system. This value also agrees with the data that Shirato et al. [12] obtained from paddy fields in Thailand. The rate of increase in SOC stock resulting from changes in land-use and adoption of recommended farming practices, follows a sigmoid curve that attains the maximum 5-20 years after adoption of recommended farming practices [8]. In addition, the amount of organic carbon stored in paddy soils is greater than in dry field soils, due to different biochemical processes and mechanisms specifically caused by the presence of floodwater in paddy soils [13]. These results show organic rice farming has a lot of potential to improve soil carbon sequestration and it may also mitigate global warming in Indonesia.

The humid tropic condition covers a large area in west Java with very high annual rainfall $(>200 \mathrm{~cm})$. Tropical evergreen forests are the climax vegetation, and crop production is limited by low fertility and soil acidity due to leaching and rapid invasion by weeds. On suitable soils, notably on rice paddies, intensive food cropping systems exist [14]. In general, if crop residues are returned and supplemented with nutrient inputs, these systems maintain adequate soil organic matter and production levels in the humid tropic regions [15]. However, burning crop residue is common practice in the conventional rice production system in west Java. When stubble is removed or burned, only the root systems are recycled. The SOC contents of these managed paddy soils were very low, for example, Kyuma [16] described low SOC content in Indonesia (Ave. $=1.39 \%, \mathrm{n}=44$ ) resulting from the widespread practice of burning rice straw at the end of the cropping cycle. Our data reveals that SOC contents in the organic rice paddy soils were higher than in the conventional managed soils, due to appropriate organic matter input such as bochashi.

Organic farming helped to reduce the cost of rice production (Figure 4). For example, conventional farmers had to pay $1,410,000 \mathrm{Rp}$ (rupiah) for chemical fertilizers, while organic farmers only had to 
pay 30,000 Rp for the bochashi organic fertilizer. Therefore, organic farming could cut $90 \%$ of the total cost of rice production.

Figure 4. Costs for farming (Rp per hectare; upper panel) and labor (hrs per hectare; lower panel) needed for organic and conventional rice farming in west Java.

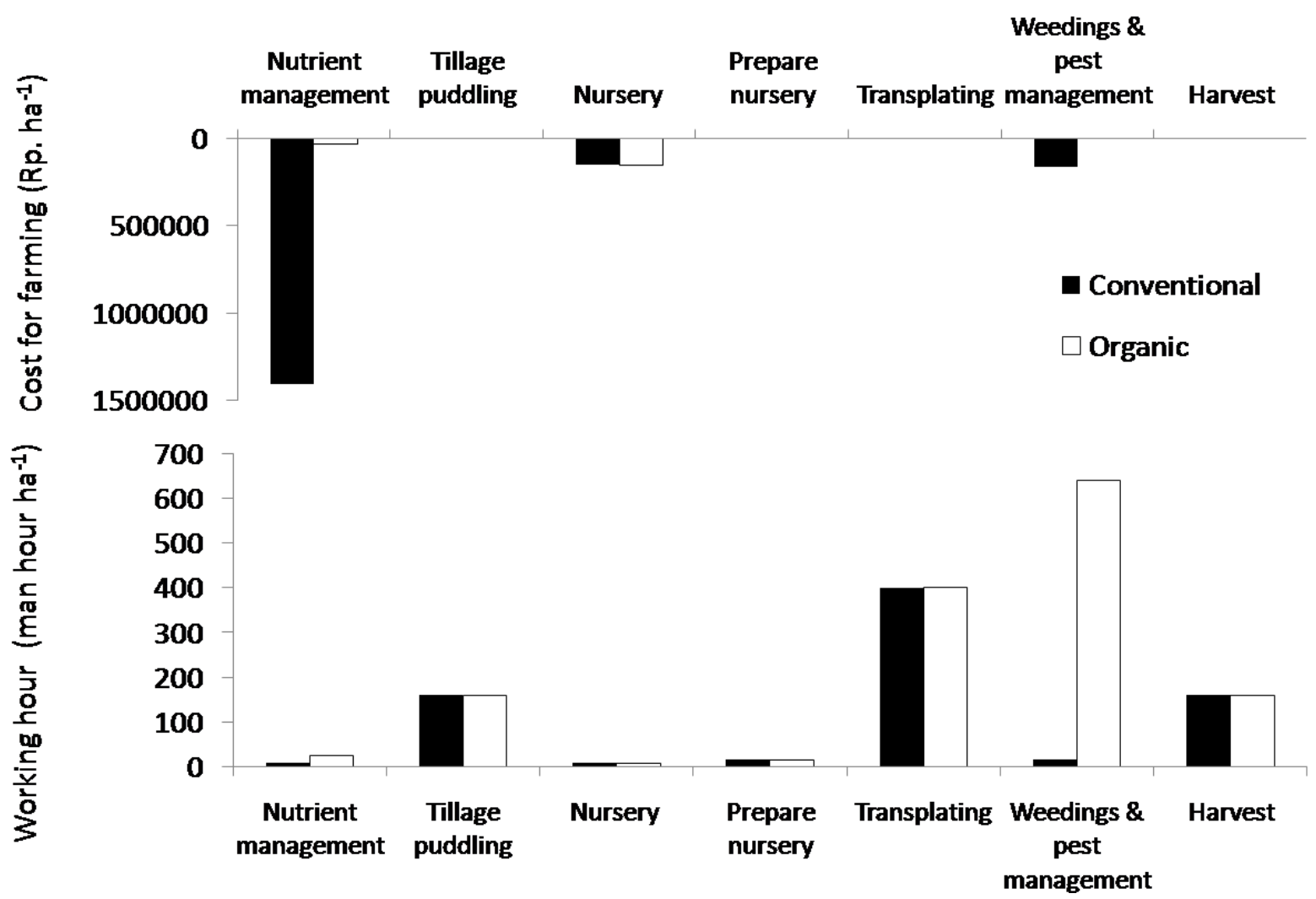

According to the latest data, farming with chemical fertilizers is on average twice as expensive as the use of organic products, while production levels are the same, if not a fraction higher in the organic sector [17]. This indicates that the economic crisis has helped to boost the growth of Indonesia's organic farming sector. The organic system required more labor to apply the organic fertilizer and weeding. The amount of organic fertilizer applied was $2 \mathrm{Mg} \mathrm{ha}^{-1}$ for each rice growing season, which was four-times greater than conventional farming, due to the lack of appropriate technology for application of the organic fertilizer. Weeding in Indonesia is mainly done by hand, and while there are also traditional weeding tools called "landak" (Figure 2), these tools still require a lot of manual labor. Total labor time for rice cultivation was 768 man hours ha $^{-1}$ for the conventional system while it was almost twice as high, 1,406 man hours ha ${ }^{-1}$, for the organic system.

Table 2 shows the gross profit and wages per working hour between the organic and conventional farming systems. The yield in the organic farming system was lower than in the conventional, while the price of organic rice was $18 \%$ higher than conventionally-grown rice, resulting in almost the same gross profits for organic and conventional farming. 
Table 2. Comparison of gross profit and hourly wages between organic and conventional farming system.

\begin{tabular}{lccrc}
\hline Management & $\begin{array}{c}\text { Yield }^{\mathbf{1}} \\
\text { (without husk) }\end{array}$ & ${\text { Price }\left(\mathbf{R p ~ k g}^{\mathbf{- 1}}\right)}^{\text {Gross Profit }}$ & $\begin{array}{c}\text { Hourly Wage } \\
\left(\mathbf{R p ~ h a}^{\mathbf{- 1}}\right)\end{array}$ & $\begin{array}{c}\text { Ho } \\
(\mathbf{R p})\end{array}$ \\
\hline Organic & $3.2 \mathrm{Mg}$ & 6,500 & $20,800,000$ & 2,955 \\
Conventional & $4.1 \mathrm{Mg}$ & 5,500 & $22,550,000$ & 5,872 \\
\hline
\end{tabular}

${ }^{1}$ Yields were obtained by sampling in September, 2008.

${ }^{2}$ Hourly wages were calculated as the cost share of total benefits to the landowner, manager and worker.

Wages per working hour in the organic system, however, were significantly lower, only about half those in the conventional system. The increased man-hour required in the organic system results in a lower hourly return and has been a major factor limiting the expansion of this farming system in west Java.

According to the soil analysis, organic farming showed significantly higher SOC storage, which may help not only to mitigate global warming, but also to establish a sustainable food system in Indonesia. Organic paddy rice farmer also has potential to improve soil quality, reduce the cost of chemicals that have recently been increasing with the price of fossils fuels, and increase farmers' incomes due to its higher price. However, organic farming requires intensive labor such as weeding and applying bocashi fertilizer to the fields.

In the study area, profits from rice production were shared among the land owners, farmers (managers), and workers, but workers received only about $20 \%$ of the yield base of rice production. This suggests that by converting conventional farming to organic farming, land owners and farmers can increase their profits, while workers receive relatively little added benefit, despite more work. Thus, while organic farming has great potential to improve environmental quality, it also creates social justice problems in Indonesia.

From an interview with a worker who was a member of women group workers in Shitogede, a strongly positive opinion regarding organic farming was received (Figure 5). The worker stated clearly "the quality of organic rice is excellent, organic rice can maintain the good flavors after cooking for long hours". Although we need a scientific evaluation of the rice quality of organic and conventional rice, her opinion suggests that the organic rice farming in Bogor Indonesia was strongly supported by the disinterest works that were provided by many female workers. These disinterest works also brought the benefit to improve the soil quality. 
Figure 5. One of the female organic rice production workers (47 years old) replied "Organic rice is delicious compare with conventional rice using chemical fertilizer. I do not care so much about weeding because we really want to have organic rice with my family" (Situgede, Bogor, Indonesia).

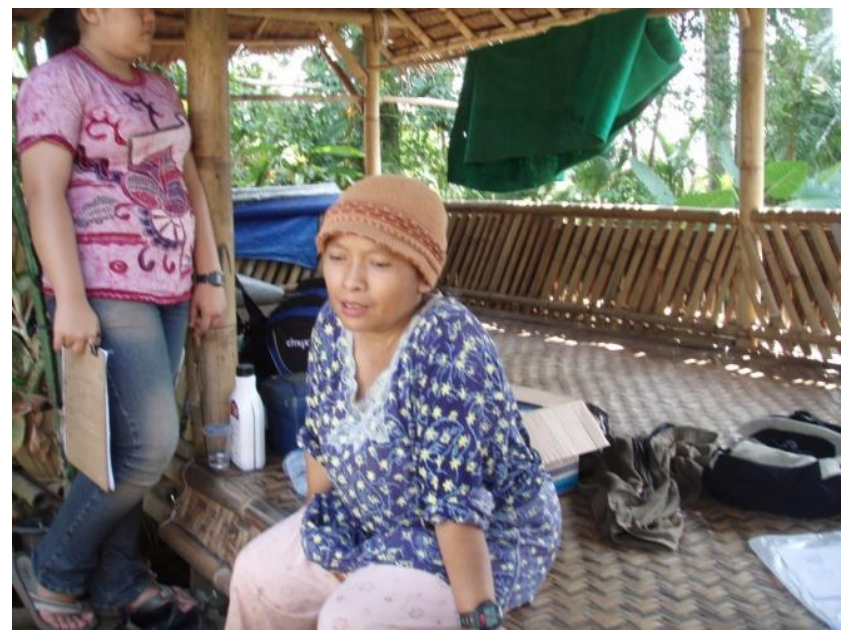

As local environmental quality becomes increasingly degraded by agricultural practices, the importance of protecting and restoring soil resources is being recognized by the world community [18-20]. Sustainable management of soil received strong support at the Rio Summit in 1992 as well as at Agenda 21 [21], the UN Framework Convention on Climate Change [22], in articles 3.3 and 3.4 of the Kyoto Protocol [23], and elsewhere. These conventions are indicative of the recognition by the world community of the strong links between soil degradation and desertification on the one hand, and loss of biodiversity, threats to food security, increases in poverty, and risks of accelerated greenhouse effects and climate change on the other. This situation suggests that a global support network system is needed to conserve the local environment such as Indonesia's organic farmlands.

To develop the renewable agriculture for enhancing sustainability, the combination approach of biophysical with socio-economic aspects of an agricultural system will be needed. Although this research data is limited to the discussion of organic farming in Indonesia, this research data highlights the cutting edge of benefits and problems of organic farming in Indonesia. Therefore, further collaboration researches between tropical countries and developed countries will be necessary to develop the sustainable agriculture for the global environment.

\section{Conclusions}

The use of bochashi organic fertilizer as an alternative in tropical paddy soils of west Java has resulted in increased soil organic carbon storage and gross benefits for farming. Therefore, organic farming for rice production may help not only to mitigate global warming by carbon sequestration, but also to establish a sustainable food system in Indonesia. Although, land owners and farmers can increase their profits by converting conventional farming to organic farming, the workers must work harder and they receive relatively little added benefit due to the sharecropping system. Therefore, 
political and social incentives will be required based on the common understanding that management of soil and agro-ecosystems will be essential to develop a society in this century where nature and humans coexist.

\section{Acknowledgements}

This work was supported in part by MEXT through Special Coordination Funds for Promoting Science and Technology, as part of the research project for "Sustainable agriculture practices to mitigate and adapt to global warming" undertaken by the Institute for Global Change Adaptation Science, Ibaraki University.

\section{References}

1. Gliessman, S.R. Agroecology: The Ecology of Sustainable Food System; CRC press: Boca Raton, FL, USA, 2006.

2. Pimentel, D.; Harvey, C.; Resosudarmo, P.; Sinclair, K.; Kurz, D.; McNair, M.; Crist, S.; Shpritz, L.; Fitton, L.; Saffouri, R.; Blair. R. Environmental and economic costs of soil erosion and conservation benefits. Science 1995, 267; 1117-1122.

3. Millennium Ecosystem Assessment: Ecosystems and Human Well-Being: Synthesis; World Resource Institute: Washington, DC, USA, 2005.

4. Syuaib, M.F. Perspective of sustainable agriculture in Indonesia: Keep growing in harmony with environment. In Final Report of International Post Graduate GP Workshop on "From Environmental to Sustainable Science: Thinking the Shift and the Role of Asian Agricultural Science”; Ibaraki University: Ibaraki, Japan, 2009; pp. 93-99.

5. Syuaib, M.F. Farming system in Indonesia and its carbon balance feature. In Final Report of International Symposium "Food and Environmental Preservation in Asian Agriculture"; Ibaraki University: Ibaraki, Japan, 2006; pp. 26-30.

6. Komatsuzaki, M.; Ohta, H. Soil management practice for sustainable agroecosystem. Sustain. Sci. 2007, 2, 103-120.

7. Heieh, S.C. Organic farming for sustainable agriculture in Asia with special reference to Taiwan experience, 2005; Available online: http://www.agnet.org/library/eb/558/ (accessed on 31 January 2010).

8. Lal, R. Soil carbon sequestration impacts on global climate change and food security. Science 2004, 304, 1623-1627.

9. Marriott, E.E.; Wander, M.M. Total and labile soil organic matter in organic and conventional farming systems. Soil Sci. Soc. Am. J. 2006, 70, 950-959.

10. Pimentel, D.; Hepperly, P.; Hanson, J.; Douds, D.; Seidel, R. Environmental, energetic, and economic comparisons of organic and conventional farming systems. BioScience 2005, 55, 573-582.

11. Nelson, D.W.; Sommers, L.E. Total carbon, organic carbon, and organic matter. In Methods of Soil Analysis Part 2. Chemical and Biological Properties, 2nd ed.; Page, A.L., Miller, R.H., Keeney, D.R., Eds.; American Society of Agronomy: Madison, WI, USA, 1982; pp. 539-579. 
12. Shirato, Y.; Paisancharoen, K.; Sangtong, P.; Nakviro, C.; Yokozawa, M.; Matsumoto, N. Testing the Rothamsted Carbon Model against data from long-term experiments on upland soils in Thailand. Eur. J. Soil Sci. 2005, 56, 179-188.

13. Katoh, T. Carbon accumulation in soils by soil management, mainly by organic matter application-Experimental results in Aichi prefecture. Jpn. J. Soil Sci. Plant Nutr. 2003, 73, 193-201.

14. Bronson, K.F.; Cassman, K.G.; Wassmann, R.; Olk, D.C.; van Noordwijk, M.; Garrity, D.P. Soil carbon dynamics in different cropping systems in principal ecoregions of Asia. In Management of Carbon Sequestration in Soil; Lal, R., Kimble, J.M., Follett, R.F., Stewart, B.A., Eds.; CRC Lewis Publishers: Boca Raton, FL, USA, 1998; pp. 35-57.

15. Hutchinson, J.J.; Campbell, C.A.; Desjardins, R.L. Some perspectives on carbon sequestration in agriculture. Agri. Forest Meteorol. 2007, 142, 288-302.

16. Kyuma, K. Paddy soils of Japan in comparison with those in Tropical Asia. In Proceedings of First International Symposium on Paddy Soil Fertility, Chiangmai, Thailand, 6-13 December 1988; pp. 5-19.

17. The Jakalta post economic crisis helps boost growth in Indonesia's organic fertilizer sector, 2009; Available online: http://www.thejakartapost.com/news/2009/03/02/economic-crisis-helps-boostgrowth-indonesia039s-organic-fertilizer-sector.html (accessed on 31 January 2010).

18. Barford, C.C.; Wofsy, S.C.; Goulden, M.L.; Munger, J.W.; Pyle, E.H.; Urbanski, S.P.; Saleska, S.R.; Fitzjarrald, D.; Moore, K. Factors controlling long- and short-term sequestration of atmospheric $\mathrm{CO}_{2}$ in a mid-latitude forest. Science 2001, 294, 1688-1691.

19. Lal, R. Soil erosion impact on agronomic productivity and environment quality. Crit. Rev. Plant Sci. 1998, 17, 319-464.

20. Lal, R. World cropland soils as source or sink for atmospheric carbon. Adv. Agron. 2001, 71, 145-191.

21. UNCED Agenda 21: Programme of action for sustainable development, Rio declaration on environment and development, statement of principles. In Final Text of Agreement Negotiated by Governments at the United Nations Conference on Environment and Development (UNCED); United Nations Development Programme (UNDP): New York, NY, USA, 1992; pp. 3-14.

22. UNFCCC United Nations Framework Convention on Climate Change; United Nations: New York, NY, USA, 1992.

23. UNFCCC Kyoto Protocol to the United Nations Framework Convention on Climate Change; United Nations: New York, NY, USA, 1998; Available online: http://unfccc.int/resource/docs/ convkp/kpeng.html (accessed on 31 January 2010).

(C) 2010 by the authors; licensee Molecular Diversity Preservation International, Basel, Switzerland. This article is an open-access article distributed under the terms and conditions of the Creative Commons Attribution license (http://creativecommons.org/licenses/by/3.0/). 